\begin{tabular}{|c|c|c|}
\hline & $\begin{array}{c}\text { Port Said Engineering Research Journal } \\
\text { Faculty of Engineering - Port Said University } \\
\text { Volume 16 No. 2 pp.: 61:67 }\end{array}$ \\
\hline
\end{tabular}

\title{
Structural design of double hull oil tankers for collision
}

\author{
EL-Sayed Hussein Hegazy ${ }^{1}$, Sherif Farouk Badran ${ }^{2}$, Samy Adly Youssef ${ }^{3}$ \\ ${ }^{1}$ Prof. of ship structures, Faculty of engineering, Port said university, E-mail: dr elsayed hegazy@yahoo.com \\ ${ }^{2}$ Lecturer, Arab Academy For science, Technology and Maritime Transport, P.O. Box 1029, Miami, Alexandria, Egypt, \\ E-mail: Sherif badran@yahoo.com \\ ${ }^{3}$ Instructor, Arab Academy For science, Technology and Maritime Transport, P.O. Box 1029, Miami, Alexandria, Egypt, \\ E-mail: samyoussef1982@hotmail.com
}

\begin{abstract}
This paper deals with the problem of double hull oil tankers loss due to the reduction of their longitudinal strength following a collision (and not due to lack of buoyancy or stability which is another problem). For this purpose the theoretical procedure which was developed by Hegazy to calculate the residual longitudinal strength of a struck ship after collision, is applied to double hull oil tanker to find out a relation between the extent of damage resulting from collision and the strength of the ship after collision. The residual strength of three double hull oil tankers is studied. The modulus of sections of these ships before and after damage were calculated and were compared with the minimum modulus of section required by the common structural rules. A new concept of structural safety for ship's hull is introduced based on the residual strength of ships after collision.
\end{abstract}

Key Words: Collision, Critical Penetration, Double Hull Tanker, Residual Longitudinal Strength, Modulus of section, Structural Safety.

\section{Nomenclature}

A Total cross sectional area before damage. $\left(\mathrm{m}^{2}\right)$

$A_{D} \quad$ Total cross sectional area of plating and longitudinal stiffeners in the deck before damage. $\left(\mathrm{m}^{2}\right)$

$A_{I B} \quad$ Total cross sectional area of plating and longitudinal stiffeners in the inner bottom before damage. $\left(\mathrm{m}^{2}\right)$

$A_{O B} \quad$ Total cross sectional area of plating and longitudinal stiffeners in the outer bottom before damage. $\left(\mathrm{m}^{2}\right)$

$A_{S} \quad$ Total cross sectional area of plating and longitudinal stiffeners in the one side before damage. $\left(\mathrm{m}^{2}\right)$

$A_{H} \quad$ Total cross sectional area of plating and longitudinal stiffeners in one longitudinal bulkhead before damage. $\left(\mathrm{m}^{2}\right)$

$B \quad$ Moulded breadth measured amidships. (m)

D $\quad$ Moulded depth to upper deck. (m)

$f_{y} \quad$ Yield stress of the material. $\left(\mathrm{kN} / \mathrm{m}^{2}\right)$

$f_{U D} \quad$ Ultimate longitudinal stress in ship deck. $\left(\mathrm{kN} / \mathrm{m}^{2}\right)$

$f_{U H} \quad$ Ultimate longitudinal stress in ship longitudinal bulkhead. $\left(\mathrm{kN} / \mathrm{m}^{2}\right)$

$f_{U S} \quad$ Ultimate longitudinal stress in ship side. $\left(\mathrm{kN} / \mathrm{m}^{2}\right)$

The distance of the plastic neutral axis below the center of deck area. (m)

Bending moment coefficient

Double bottom height. (m)

Inner bottom area factor.

Outer bottom area factor.

Deck area factor.

Longitudinal bulkhead area factor.

Side area factor.

Ship double bottom height to the moulded depth ratio.

Distance of the plastic neutral axis below the center of deck area to moulded depth ratio.

Deck strength factor.

Longitudinal bulkhead strength factor.

Side strength factor. 


\section{Abbreviations}

$A B S \quad$ American Bureau of Shipping.

CSR Common structural rules.

DHT Double hull tanker.

IACS International Association of Classification Societies.

VLCC Very large crude carrier.

\section{Introduction}

The collision accidents continue to occur in spite of continuous efforts to prevent them. With the increasing demand for safety at sea and protection of the environment, it is of great interest to be able to predict an accident, assess its consequences and ultimately minimize the damage of an accident to ships and the environment.

There has been a growing interest in reducing the risk of oil spillage due to accidents involving oil tankers and other vessels which carry potentially polluting and / or hazardous cargo.

The double hull design concept is one of the effective ways for oil pollution prevention during collision and accidents of oil tankers. However, not all of the design requirements for structural scantlings and arrangements of double hulls are sufficiently well advanced.

Regarding the concept of critical penetration which were introduced by Hegazy[1], some definitions which extend the traditional classification of ships' collision "major" and "minor", have been introduced as follows [1]:

- Minor collision

This is defined as one in which the cargo tanks remain intact, irrespective of whether the struck vessel in question has single or double skin.

- Critical minor collision

This is the minor collision beyond which rupture of the struck ships' hull in way of a cargo tank occurs with the consequence of cargo spillage.

- Major collision

This is used to describe a collision which causes large inelastic strains and fracture of the struck ship's hull in way of a cargo tank and the striking bow starts to penetrate the hull of the struck ship (i.e. oil spillage occurs).

- Critical major collision

This is used to describe a major collision which causes a critical damage (i.e. critical penetration occurs) and, hence, the residual longitudinal strength of the struck ship will reach its critical value.
- Back-break collision

This is used to describe a major collision which causes a severe damage and, hence, the struck ship will be broken into two due to the loss of her longitudinal strength after collision.

Consequently, a ship may collapse after a collision because of inadequate longitudinal strength, and it is important to keep the residual strength of damaged ship after collision at a certain level in order to avoid additional catastrophic consequences.

The main purpose of this study is to develop the theoretical calculations of the residual longitudinal strength of a struck double hull oil tanker after collision.

\section{Literature survey}

In 1959 Minorsky [2] introduced the most well known empirical approach to collision analysis. His simple formula has been widely used in ship collision analysis because of its simplicity. Minorsky analyzed 26 collision cases of full scale ship accidents and developed an empirical formula which indicated that the energy absorption by a ship during a collision is simply proportional to the volume of the destroyed material.

Hegazy investigated the possibility of a single hull struck ship being broken into two parts after collision due to the loss of her longitudinal strength[1]. The concept of the ultimate bending strength developed by Caldwell [3] has been used to calculate the transverse extent of damage (i.e. penetration) to the struck ship after collision, as well as to develop a procedure to find the critical penetration (and, hence, the corresponding critical residual strength) beyond which the struck ship might be broken into two if the longitudinal bending moment subsequently exceeds the "design value" [1]. In addition, Hegazy proposed a simple method, to estimate the amounts of energy absorbed by different parts of ship structures during a collision. His formulae were derived by using theoretical plastic analysis of various structural failure mechanics of different ship's structural members to evaluate the total absorbed energy by the struck ship and striking vessel's structures during collision[8]. Some related results are represented in [4]. 
Paik [6] has developed a fast and reasonably accurate method for exploring the collapse of the hull girder in the damaged condition. Location and amount of collision damage are defined based on the ABS Safe Hull guide [5].

Wang (2002) [7] produced a method which investigated the longitudinal strength of ships with damages due to grounding or collision accidents, based on theoretical analysis.

A practical example is the use of a small Monte Carlo optimization [11]. A new formulation is proposed by Liu for the analysis of the impact mechanics of ship collisions that can be applied to both $2 \mathrm{D}$ and $3 \mathrm{D}$ cases [ 12 ]. Pedersen presented a review of prediction and analysis tools for collision and grounding analyses and to outline a probabilistic procedure for which these tools can be used by the maritime industry to develop performance based rules to reduce the risk associated with human, environmental and economic costs of collision and grounding events [13]. Liu et.al. presented the results of integrated elasto-plastic analyses of ship-iceberg collisions based on continuum mechanics modeling of both bodies. The collision simulation was simplified by splitting the problem into external and internal mechanics, which are both discussed in detail. A simplified formulation was used to obtain the demand for energy dissipation in a shipiceberg collision. The internal mechanics was assessed by means of the explicit nonlinear code LS-DYNA. A new iceberg material model was used to simulate the iceberg behavior during the impact [14].

\section{Relation between the extent of damage and the residual longitudinal strength}

For the purpose of introducing the ultimate strength calculations, the actual structure in figure 1 is represented in the simplified form shown in figure 2 . $A_{D}, A_{I B}$ and $A_{O B}$ were assumed to be spread uniformly over the breadth $\mathrm{B}$, while $\mathrm{A}_{\mathrm{S}}$ and $\mathrm{A}_{\mathrm{H}}$ were assumed to be spread uniformly over the depth $\mathrm{D}$.

The damaged section can be taken at the mid-ship section, where the maximum value of the working bending moment as well as the probability of collision is likely to occur. Assume that after a collision the damage section of the struck ship lost the following parts: one side shell plating, a part of inner and outer bottom and deck plating, see figure 3 . The inner hull longitudinal bulkhead remains intact.

The deck, inner and outer bottom area for the struck ship are reduced after collision to $\eta A_{D}, \eta A_{I B}$ and $\eta A_{O B}$.
Where, $\eta$ is the residual area coefficient for (the area after damage divided by the area before damage) and is given by;

$\eta=\frac{B-w}{B}=1-w / B$

Where

$w=$ penetration (i.e. extent of damage in the transverse direction) which is less than or equal to the wing tank width (b) $(w \leq$ b) as shown in figure 3. (i.e. the inner hull longitudinal bulkhead remains intact)

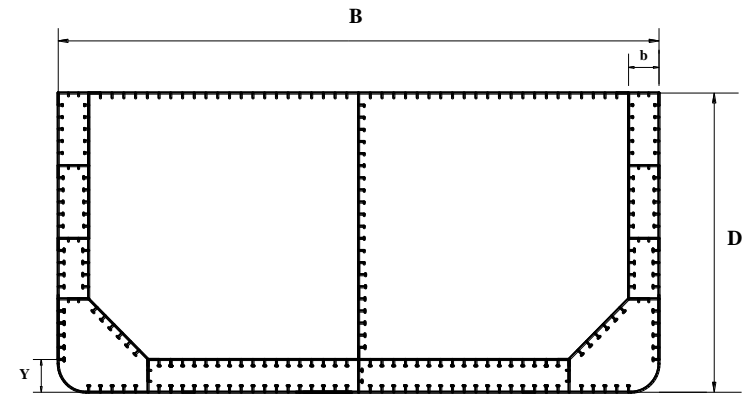

Fig. 1. Actual mid-ship section of double hull oil tanker before damage.

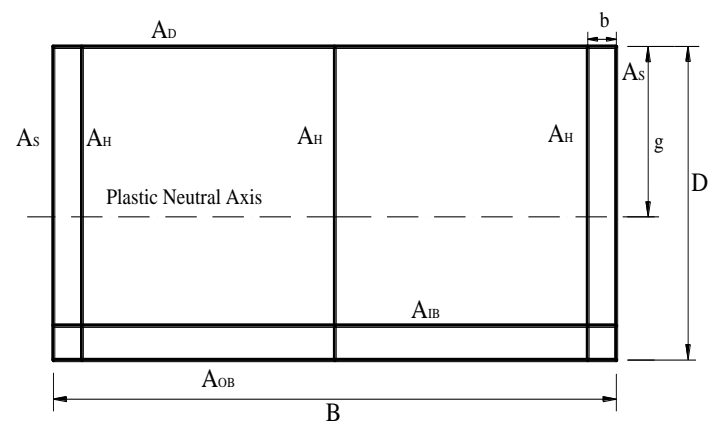

Fig.2.Idealized mid-ship of double hull oil tanker before damage.

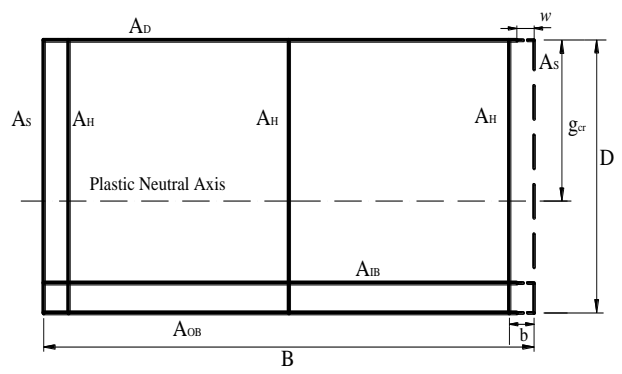

Fig. 3. Structural configuration (smearing) of double hull tanker after damage.

Clearly this is an idealized model, which can be drawn quickly for the given ship section. It would not be difficult in principle to take into account more exactly the actual distribution of area around the crosssection or other damage schemes.

For a ship two situations are to be considered, hogging and sagging and in general the ultimate bending strength will differ for the two cases. Both 
cases need to be considered and compared with the predicted maximum applied hogging and sagging moments. In what follows only sagging condition will be treated, although the method can be equally well applied to the hogging condition. [8]

Figure 4 shows the longitudinal average stress distribution over the cross-section of the struck ship after damage in the limit (or ultimate strength) condition. In the inner, outer bottom structure and in the sides below the neutral axis (whose position is to be determined), the full yield stress in tension side has developed. On compression side, the deck structure and the side above the neutral axis will have reached their ultimate load-carrying capacities, and because of buckling of plating and / or stiffeners, the effective longitudinal stress at any point in these structures will in general be less than the yield stress of the material [3].

Caldwell replaced the nearest to the actual distribution of longitudinal stress at collapse by an equivalent average ultimate longitudinal stress in $\operatorname{deck} f_{U D}$, in the side $f_{U S}$ and in longitudinal bulkhead $f_{U H}$ by introducing deck, side and bulkhead strength factors given, respectively, [3] as;

$$
\begin{aligned}
& \emptyset_{D}=f_{U D} / f_{y} \\
& \emptyset_{S}=f_{U S} / f_{y} \\
& \emptyset_{H}=f_{U H} / f_{y}
\end{aligned}
$$

$f_{y}$ is assumed to have the same value in tension and compression. The ultimate strength factors $\emptyset_{D}, \emptyset_{S}$ and $\emptyset_{H}$ play an important role in ultimate strength calculation and thus are estimated by the method that seems most appropriate (Faulkner, 1965). [8]

Considering the area for each ship's structural item related to the total mid-ship cross section area in term of "area factor" and called $\alpha$ where,

$$
\begin{gathered}
\propto_{s}=A_{s} / A \\
\propto_{i}=A_{I B} / A \\
\propto_{o}=A_{O B} / A \\
\propto_{H}=A_{H} / A \\
\propto_{D}=A_{D} / A
\end{gathered}
$$

Where, $A=A_{D}+A_{I B}+A_{O B}+2 A_{S}+3 A_{H}$

Using the condition of zero net longitudinal force over the cross section, as shown in figure 4, we get:

$\gamma=\frac{g}{D}=\frac{\propto_{S}+3 \propto_{H}+\eta\left(\propto_{i}+\propto_{o}-\alpha_{D} \emptyset_{D}\right)}{\alpha_{S}\left(1+\emptyset_{S}\right)+3 \propto_{H}\left(1+\emptyset_{H}\right)}$

It must be noticed that equation (2) is derived for the damaged model as shown in figure 3 , where the number of intact longitudinal bulkheads after collision is 3 .
For " $n$ " number of intact longitudinal bulkheads after collision equation (2) will be

$\gamma=g / D=\frac{\propto_{S}+n \propto_{H}+\eta\left(\propto_{i}+\propto_{o}-\alpha_{D} \emptyset_{D}\right)}{\alpha_{s}\left(1+\emptyset_{S}\right)+n \propto_{H}\left(1+\emptyset_{H}\right)}$

The internal moment of resistance corresponding to the stress distribution in the limit condition is founded by taking moment about the plastic neutral axis of the forces in deck, side and bottom. Denoting this "Ultimate moment" by $\left(M_{U}\right)$ we get:

$M_{U}=\frac{f_{y} A D}{2}\left[\begin{array}{c}2 \eta\left(\gamma \emptyset_{D} \propto_{D}+\propto_{i}(1-\gamma-\beta)+\propto_{o}(1-\gamma)\right) \\ +\gamma^{2}\left(\emptyset_{s} \propto_{s}+3 \emptyset_{H} \propto_{H}\right)+(1-\gamma)^{2}\left(\propto_{s}+3 \propto_{H}\right)\end{array}\right]$

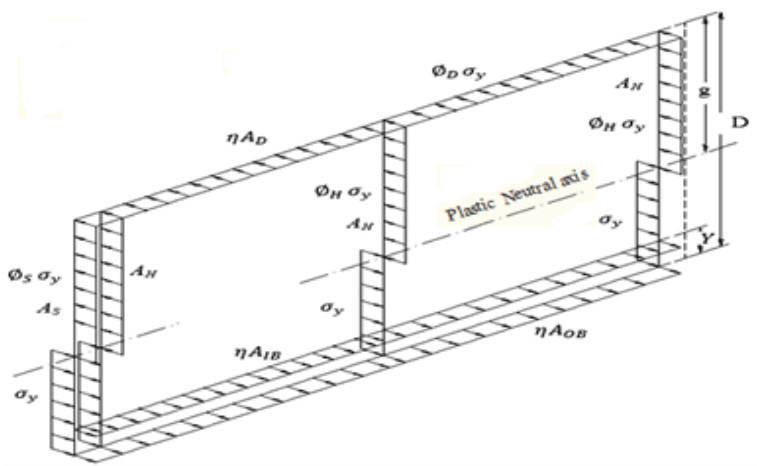

Fig.4. Equivalent average ultimate longitudinal stress distribution over the mid-ship section of an oil tanker in damaged condition.

For any number " $n$ " of intact longitudinal bulkheads after damage the value of $M_{U}$ will be

$M_{U}=\frac{f_{y} A D}{2}\left[\begin{array}{c}2 \eta\left(\gamma \emptyset_{D} \propto_{D}+\propto_{i}(1-\gamma-\beta)+\propto_{o}(1-\gamma)\right) \\ +\gamma^{2}\left(\emptyset_{S} \propto_{s}+n \emptyset_{H} \propto_{H}\right)+(1-\gamma)^{2}\left(\propto_{S}+n \propto_{H}\right)\end{array}\right]$

Where, $\beta=Y / D$

Equation (5) was derived for the damaged model shown in figure 3 for $w \leq \mathrm{b}$ (i.e. all longitudinal bulkheads are remained intact after collision- no oil spill)

For $w>\mathrm{b}$, in this case the number of intact bulkhead (n) in equation (5) will represent only the number of the remaining intact bulkheads- oil spill occurs.

For single bottom, single side, without longitudinal bulkheads oil tanker (old ones), the ultimate moment can be obtained by putting

$n=0, \propto_{i}=0$ and $\beta=0$ in equation (5), we get:

$M_{U}=\frac{f_{y} A D}{2}\left[\begin{array}{c}2 \eta\left(\gamma \emptyset_{D} \propto_{D}+\propto_{o}(1-\gamma)\right) \\ +\gamma^{2}\left(\emptyset_{s} \propto_{s}\right)+\left(\propto_{s}\right)(1-\gamma)^{2}\end{array}\right]$

\section{Critical penetration}

The introduction of the ultimate bending strength enables the designer to find the true margin of safety, 
as the ratio between the ultimate bending moment and the working bending moment experienced by the ship among waves (as obtained from wave and loading data). Obviously the ultimate bending strength of the struck ship will be decreased due to the damage resulting from collision (see equation (5)). The value of the working bending moment in the damaged condition can be obtained from longitudinal strength calculations by considering the damaged condition as one among the other conditions at which longitudinal bending moment are to be obtained. The damaged section can be taken at the mid-ship section, where the maximum value of the working bending moment as well as the probability of collision is likely to occur.

As explained in ref. [1], if it happens that, after a collision, the transverse penetration is so severe that the ultimate bending moment after damage (as calculated from equation (5)) is equal to the working bending moment (as discussed above); this means that the margin of safety is unity and any increase in the value of the working bending moment would result in the structural collapse of the ship. Following the above discussion Hegazy [1] introduced the term "critical penetration" $\left(w_{c r}\right)$ to describe the transverse penetration in the struck ship, which results in the equality of the ultimate bending moment of the damaged cross-section and the working one, i.e.,

$M_{U}=M$

Where

$M$ is the working bending acting at the damaged section of the struck ship obtained as discussed above. Using equation (5) and equation(7), we get:

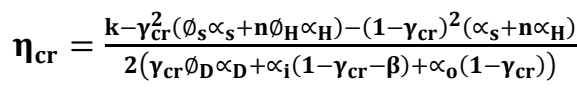

Where,

$\eta_{c r}$ is critical residual area coefficient.

$g_{c r}$ is the distance of the plastic neutral axis below the centre of deck area in the critical major collision.

$\gamma_{c r}=g_{c r} / D$

$\gamma_{c r}$ is the distance of the plastic neutral axis below the centre of deck area to moulded depth ratio in critical major collision.

Where, $k=\frac{2 M}{f_{y} A D}$

For single bottom, single side tanker (Pre-MARPOL oil tanker), the $\eta_{c r}$ can be obtained by putting $n=0$, $\alpha_{i}=0$ and $\beta=0$ in equation (8) to be the following:

$\eta_{c r}=\frac{k-\gamma_{c r}^{2}\left(\emptyset_{S} \propto_{S}\right)-\left(1-\gamma_{c r}\right)^{2}\left(\propto_{S}\right)}{2\left(\gamma_{c r} \emptyset_{D} \alpha_{D}+\propto_{o}\left(1-\gamma_{c r}\right)\right)}$
In this critical condition equation (1) for the residual area coefficient will be

$$
\begin{aligned}
\eta_{c r} & =\frac{B-w_{c r}}{B}=1-w_{c r} / B \quad \text { or } \\
w_{c r} & =B\left(1-\eta_{c r}\right)
\end{aligned}
$$

Where, $w_{c r}$ is the critical penetration (i.e. critical extent of damage in transverse direction).

By using equations (3) and (8), one can get the following equation for $\gamma_{c r}$ :

$\gamma_{c r}^{2}+\frac{\mu}{\zeta} \gamma_{c r}+\frac{\psi}{\zeta}=0$

Solving equation (11) for $\gamma_{c r}$, we get:

$\gamma_{c r}=0.5\left[\frac{-\mu}{\zeta} \pm \sqrt{\left(\frac{\mu}{\zeta}\right)^{2}-\frac{4 \psi}{\zeta}}\right]$

Where,

$$
\begin{gathered}
\zeta=\left(\alpha_{D} \emptyset_{D}-\propto_{i}-\propto_{o}\right)\left[\begin{array}{c}
2 \propto_{s}\left(1+\emptyset_{s}\right)+ \\
2 n \propto_{H}\left(1+\emptyset_{H}\right) \\
-\left(\emptyset_{s} \propto_{s}+n \emptyset_{H} \propto_{H}\right) \\
-\left(\propto_{s}+n \propto_{H}\right)
\end{array}\right] \\
\mu=\left(\propto_{o}+\propto_{i}(1-\beta)\right)\left[\left(2 \propto_{s}\left(1+\emptyset_{s}\right)\right.\right. \\
\left.\left.+2 n \propto_{H}\left(1+\emptyset_{H}\right)\right)\right]
\end{gathered}
$$

$$
\begin{array}{r}
\psi=\left[\left(2 \propto_{s}+2 n \propto_{H}\right)\left(\propto_{i}(\beta-1)-\propto_{o}\right)\right]- \\
{\left[\left(k-\left(\propto_{s}+n \propto_{H}\right)\right)\left(\propto_{o}+\propto_{i}-\alpha_{D} \emptyset_{D}\right)\right]}
\end{array}
$$

Considering only the logical value of $\gamma_{c r}$ from equation (11) (which must be less than one), the value of ultimate bending moment $M_{U}$ can be calculated from equation (5)

\section{Assessment of residual longitudinal strength of ships after critical major collision}

After calculating the value of critical penetration as given by equation (10), the modulus of section of a struck ship being involved in critical major collision (i.e. collision which causes critical penetration) can be calculated and we shall call it as critical modulus of section $\left(Z_{\text {Critical }}\right)$.

If the penetration resulted from a collision is more than the critical one (i.e. $w>w_{c r}$ ) then the modulus of section of damaged struck ship in this case will be less than $Z_{\text {critical }}$ and the struck ship will be broken into two parts.

As case studies, three oil tankers of dead weight 45000, 150000 [9] and 97000 tonnes [10] were chosen to calculate their $\mathrm{Z}_{\text {Critical }}$. The data of the three tankers are shown in Table 1. 
For the purpose of calculations the mid-ship section of these vessels( in intact and damaged condition)were represented in a simplified structural model as shown in figure 2 , where stiffeners are smeared into the plate thickness.

The values of the critical modulus of section of the above mentioned DHT $\left(\mathrm{z}_{\mathrm{cr}}\right)$ as explained before are given in Table (2). Also, the values of the recommended after damage residual modulus of section using ABS rules [5] are shown in Table (2) as well as the ratios $Z_{r} / Z_{c r}$.

From the results given in Table (2), the average ratio between the recommended residual modulus of section as recommended by ABS rules and the critical modulus of section beyond which the ship will be broken into two parts due to loss of her longitudinal strength is about 1.5 .

\section{Table 1}

Struck ships structural characteristics

\begin{tabular}{|l|l|l|l|}
\hline & DHT 45000 & DHT 97000 & DHT 150000 \\
\hline Displacement $(\Delta)($ ton) & 54216.8 & 114117.6 & 174418.6 \\
\hline Length between perpendiculars (LBP) $(\mathrm{m})$ & 190.5 & 238 & 261 \\
\hline Moulded breadth $(\mathrm{B})(\mathrm{m})$ & 29.26 & 43 & 50 \\
\hline Moulded depth to upper deck $(\mathrm{D})(\mathrm{m})$ & 15.24 & 21 & 25.1 \\
\hline Designed draft $(\mathrm{T})(\mathrm{m})$ & 10.58 & 13.5 & 16.76 \\
\hline Double bottom height $(\mathrm{Y})(\mathrm{m})$ & 2.1 & 2.3 & 3.34 \\
\hline Wing width $(\mathrm{b})(\mathrm{m})$ & 2.438 & 2.18 & 3.34 \\
\hline Block coefficient $\left(\mathrm{C}_{\mathrm{b}}\right)$ & 0.89 & 0.76 & 0.78 \\
\hline
\end{tabular}

Table 2

Comparison between $\left(Z_{c r}\right)$ and $\left(Z_{\mathrm{r}}\right)$ for candidate ships.

\begin{tabular}{rccc}
\hline Vessel & $\begin{array}{c}\text { Critical residual modulus of } \\
\text { section after damage in } m^{3} \\
\left(Z_{c r}\right)\end{array}$ & $\begin{array}{c}\text { Recommended residual section modulus } \\
\text { after damage by (ABS) in } m^{3}\end{array}$ & $Z_{\mathrm{r}} / Z_{c r}$ \\
DHT 45000 & 6.7035 & 9.2779 & 1.384 \\
DHT 97000 & 13.9159 & 20.8055 & 1.495 \\
DHT 150000 & 18.0551 & 30.1551 & 1.670 \\
\hline
\end{tabular}

\section{Conclusions}

A simplified procedure is developed to calculate the critical residual strength of a double hull tanker being involved in critical major collision (i.e. a collision which causes critical damage beyond which the ship will be broken into two). A new factor of structural safety of ship's hull has been developed and represented by the ratio between the recommended section modulus of a damaged section, and the critical residual section modulus as calculated by the method developed in this paper. This ratio $\mathrm{Z}_{\mathrm{r}} / \mathrm{Z}_{\mathrm{cr}}$ is the real factor of structural safety of a ship, since it takes into consideration the probability that a ship may be involved in critical major collision during her life time.

\section{References}

[1] Hegazy, E. H., Residual strength of ships after collision, Journal for Arab Academy for Science, Technology and Maritime Transport, Vol. 28, No. 56 (2003).

[2] Minorsky, V. U., Analysis of ship collisions with reference to protection of nuclear power plants, Journal of ship research Vol. 3, No. 2, (1959).

[3] Caldwell, J.B., Ultimate Longitudinal Strength, Trans. RINA, Vol. 107,(1965).

[4] E. El-bokl, Modern tanker design analysis for the environmental impact, PHD thesis, Maritime Transport College Arab Academy for Science, Technology and Maritime Transport, 2003.

[5] ABS, Guide for dynamic based design and evaluation of bulk carrier structures, American Bureau of Shipping, Safe Hull Project, 1995. 
[6] Paik, Anil K. Thayamballi and Yang S. H., Residual Strength Assessment of Ships after Collision and Grounding, Marine Technology, Vol. 35, (1998).

[7] Wang, G., Chen,y., Zhang,H. and HuaPeng, Longitudinal strength of ships with accidental damages, Marine Structures No.15, (2002).

[8] Faulkner, D., Witten discussion Trans., RINA, Vol. 107,(1965), p.425.

[9] A.J. Brown, Collision scenarios and probabilistic collision damage, Marine Structures No. 15,(2002), pp 336-364.

[10] Daewoo Shipbuilding Marine engineering co. (DSME), 2001, VELLA product carrier's midship section. Structure R\&D team.

[11] Chen, D., "Simplified Collision Model (SIMCOL)", Dept. of Ocean Engineering, Virginia Tech, Master of Science Thesis, May 2000.

[12] Liu, Z., Amdahl, J., A new formulation of the impact mechanics of ship collisions and its application to a ship-iceberg collision, Marine Structures, Vol.23, (2010), p.360-384

[13] Pedersen,P.T., Review and application of ship collision and grounding analysis procedures, Marine Structures, Vol.23, (2010), p. 241-262

[14] Liu,Z., Amdahl,J., Løset,S., Integrated numerical analysis of an iceberg collision with a foreship structure, Marine Structures, Vol. 24 (2011),p.377-395 